\title{
USE OF A KINETIC BIOASSAY PROCEDURE TO ESTIMATE SULFATE AND CYSTEINE CONCENTRATIONS IN SEDIMENT
}

\author{
David A. Dunnette ${ }^{1 . *}$, David P. Chynoweth ${ }^{2}$ and K. H. ManCY 3 \\ 'Environmental Science and Resources Program, Portland State University, P.O. Box 75I, Portland, \\ OR 97207, 'Agricultural Engineering Department, University of Florida, Gainesville, \\ FL 32611 \\ and ${ }^{3}$ Department of Environmental and Industrial Health, The University of Michigan, Ann Arbor, \\ MI 48109, U.S.A.
}

(First received June 1988; accepted in revised form February 1990)

\begin{abstract}
There are often difficulties in estimating the bioavailability of essential nutrients and energy sources for aquatic microorganisms involved in mediating key sedimentary biotransformations. In order to estimate rates of sulfate reduction and putrefaction in sedimentary hydrogen sulfide production, a kinetic bioassay procedure was utilized to confirm the concentrations of hydrogen sulfide precursors determined by standard analytical procedures. Results were suggestive but inconclusive that sulfide production via sulfate reduction and putrefaction adhere to the Michaelis-Menten kinetic model. Nevertheless the kinetic bioassay procedure of Wright and Hobbie (Ecology 47, 447-464, 1966) appears to be useful in estimating substrate bioavailability for cysteine and sulfate and perhaps other sedimentary substrates. In addition the method described permits reliable tracer estimates of sulfide production in freshwaters with low sulfate concentrations which might otherwise not be possible.
\end{abstract}

Key words $\rightarrow$ sulfate, cysteine, analysis, sediment, bioassay

\section{INTRODUCTION}

Estimates of biotransformation rates require knowledge of the natural substrate concentrations associated with the transformations of interest. In homogeneous media this is usually accomplished more or less directly with standard instrumental or wet chemical techniques when substrate concentrations are within detection limits. With substantially heterogeneous media such as soil or sediment, new dimensions of physico-chemical complexity must be confronted in order to estimate natural substrate concentrations, i.e. concentration which reflect nutrient or energy source availability; therefore, results obtained with classical or traditional methods may not accurately reflect availability. For example, availability of nitrogen, phosphate, sulfate and other plant growth nutrients have been of primary interest to soil scientists for decades (Freney et al., 1962, 1969; Jordan and Ensminger, 1958; Kamprath et al., 1956; Lowe, 1964, 1965; McLaren and Peterson, 1967; Paul and Schmidt, 1960, 1961). Studies of eutrophication beginning in the late 1960s focused on how algal growth is limited by nutrient availability. Many of these studies have involved investigations of the extent to which sediment bound phosphorous was available for primary production.

-Author to whom all correspondence should be addressed.

\section{Formation of hydrogen sulfide}

The overall goal of our research, reported elsewhere (Dunnette et al., 1985; Dunnette, 1989) was to evaluate the relative importance of microbial sulfate reduction and putrefaction (including desulfurization) in the production of hydrogen sulfide in anaerobic freshwater lake sediment. To determine hydrogen sulfide production rates in our investigation, it was necessary to consider the two separate bacterial processes from which sulfide is produced. Sulfate reduction is the microbial reduction of higher oxidation state inorganic sulfur species to reduced sulfur, the sulfate serving as the terminal electron acceptor from the anaerobic oxidation of organic matter in the respiratory process. Relatively few species of organisms are able to dissimilatively reduce sulfate. Putrefaction, also referred to as anaerobic decomposition, is a result of bacterial degradation of reduced organic matter, principally the protein fraction of dead organisms and discharged wastewater and is a process mediated by several genera of bacteria.

\section{Problems with chemical analysis of sediment}

In order to calculate hydrogen sulfide production rates in our studies two kinds of information were required: (1) the fraction of added ${ }^{35} S$ precursor converted to sulfide per unit time $(f / t)$ and (2) the total concentration (natural + added, $S_{\mathrm{n}}+A$ ) of sulfide precursor in sediment samples prior to 
laboratory incubation at $10^{\circ} \mathrm{C}$. The $(f / t)$ terms are readily determined from measurements of ${ }^{35} \mathrm{~S}$ in the added and recovered sulfide. The $A$ component of the concentration term is readily calculated but knowledge of $S_{\mathrm{n}}$ is normally dependent on chemical analyses.

In natural waters relatively free of sediment or detrital material the analytical value obtained by a chemical procedure for the concentration of a nutrient is often a good measure of the actual availability of that nutrient for the indigenous organisms. This is not necessarily the case with sediment. Sediment is a heterogeneous substance containing a very complex mixture of various sized organic and inorganic substances and associated living organisms. If clay minerals make up a significant portion of the inorganic matter the sediment has an immense surface area. All of the solid particles present in sediment possess capacities for absorbing, chemically or physically, molecular and ionic species present in the interstitial water. In addition parameters such as temperature, $\mathrm{pH}$ and Eh greatly affect the nature and form of many nutrients. These factors can complicate determinations of nutrient bioavailability.

It is therefore clear that chemical analytical data generated for the purpose of elucidating microbially mediated chemical transformations in sediment may be of questionable validity even though such "classical" data are traditionally accepted as having significance. A supplementary procedure may be required to provide confirmatory evidence that a given analytical technique is capable of providing data which reflects true availability of a dissolved substance for microorganisms which utilize it as either a nutrient or energy source.

An approach to the problem of substrate availability in a heterogeneous medium such as sediment was described by Wright and Hobbie (1966). Our specific objective was to utilize this kinetic bioassay procedure as a tool to guide selection of chemical analytical procedures which would provide sulfate and cysteine concentration values that reflect true biochemical availability and ones which could validly be used in estimating hydrogen sulfide production rates. A review of recent applications of the kinetic bioassay procedure in assessing availability is included in the Discussion section.

\section{METHODS}

Rate determining method

The techniques used to measure hydrogen sulfide production rates in this investigation are described elsewhere (Dunnette et al., 1985; Dunnette, 1989). Briefly ${ }^{35}$ S-labeled sulfate and cysteine were added separately to freshwater lake sediment which had been transferred to plastic disposable syringes. The syringes were allowed to incubate at $10^{\circ} \mathrm{C}$ for $2 \mathrm{~h}$ in a Dewar flask. Aliquots were taken at 30 min intervals and fixed with cadmium acetate. Sulfide was distilled by addition of $\mathrm{HCl}$, reprecipitated as cadmium sulfide and finally deposited on planchets for counting. Substrate depletion during the $2 \mathrm{~h}$ incubation ranged from approx. 1 to $5 \%$. Final labeled plus unlabeled concentrations of sulfate and cysteine varied from 4.3 to 12.3 and 2.2 to $5.6 \mathrm{mg} \mathrm{S} \mathrm{I}^{-1}$, respectively. Precision of the methods was $\pm 15 \%$.

\section{Sediment samples}

Results were obtained from the analysis of sediment samples collected from Third Sister Lake, a 4 ha moderately eutrophic lake located in Southeastern Michigan, using a special anaerobic sampling and manipulation corersyringe assembly (Dunnette et al., 1985). The samples were collected over a May-October sampling period from West Station at a depth of $15 \mathrm{~m}$. Samples used for the Michaelis-Menten and kinetic bioassay experiments were taken in late August and early September, respectively, from the same station.

\section{Rationale for analytical procedures used}

Knowledge of what concentration of sulfate and cysteine are actually biologically "available" $\left(S_{n}\right)$ is important for valid estimations of microbial transformation rates. Two procedures were selected for use in analyzing both hydrogen sulfide precursors in sediment. The first, centrifugation at $30,000 \mathrm{~g}$, involved simple phase separation. Results obtained from analysis of these samples would provide minimum rate estimates. The second general procedure used was extraction with neutral or alkaline phosphate buffer. This extractant has been widely used in soil investigations of sulfate availability (Melville et al., 1969; Lowe, 1965) and provides something approaching a maximum bioavailability value for sulfate.

The problems involved in cysteine availability are considerably more complex. Like sulfate, protein exists in soluble, colloidal and sorbed forms. Unlike sulfate, however, protein, peptides and amino acids can form exceedingly strong bonds with clay minerals. This capacity varies with $\mathrm{pH}$ and ionic strength of the medium. Clay minerals possess a net negative charge due to isomorphous substitution in the crystal structure and broken bonds on crystal edges (sediment used in this work was $40 \%$ clay). Amino acids and protein possess a net positive charge below their isoelectric point and a net negative charge above it. Thus, there is a reduced tendency for protein and amino acids to bind to clay minerals at $\mathrm{pHs}$ above about 7 where there is a deficiency of hydrogen ions and most amino acids exist as carboxylate anions. The general procedure used for cysteine extraction prior to analysis was, therefore, phosphate buffer extraction. Two buffer $\mathrm{pH}$ levels were selected which provided a moderate range of variation in sediment cysteine concentrations-pH 10 and 12 .

\section{Analysis of sulfate}

Twenty samples of sediment from the West Station were analyzed for sulfate. The method involved reduction of sulfate to sulfide, distillation of sulfide into alkaline fixative and subsequent colorimetric determination (Dunnette et al., 1985). Ten samples were extracted for $30 \mathrm{~min}$ with pH 7 buffer and then centrifuged for $30 \mathrm{~min}$ at $30,000 \mathrm{~g}$ prior to analysis of the supernatant. An equivalent set of samples were simply centrifuged prior to reduction and determination.

\section{Analysis of cysteine}

One set of 16 samples was shaken for 30 min with $\mathrm{pH} 10$ phosphate buffer prior to oxidation of the centrifuge supernatant with performic acid and elution as cysteic acid by ion exchange chromatography (Dunnette et al., 1985). A second set of 16 identical samples were extracted with $\mathrm{pH} 12$ phosphate buffer prior to oxidation, centrifugation and elution. Concentrations were determined colorimetrically with ninhydrin reagent. 


\section{Adherence to Michaelis-Menten kinetics}

The numerical solution to the determination of substrate availability using the method of Wright and Hobbie is based on the Michaelis-Menten model of enzyme kinetics,

$$
v=\frac{V(S)}{K_{m}+S}
$$

in which $v$ is the velocity at a given substrate concentration $S, V$ is the maximum obtainable velocity (when enzymes are saturated) and $\boldsymbol{K}_{\mathrm{m}}$ is the Michaelis constant (the substrate concentration when the velocity is $1 / 2 \mathrm{~V}$ ). To determine if the Michaelis-Menten model applies to hydrogen sulfide production, rates of sulfate reduction and putrefaction were determined at four concentrations ranging from 4.27 to $12.27 \mathrm{mg} \mathrm{S} \mathrm{I}^{-1}$ for sulfate and four concentrations ranging from 2.22 to $5.64 \mathrm{mg} \mathrm{Sl}^{-1}$ for cysteine using the expression of Parsons and Strickland (1962) as modified by Hobbie and Crawford (1969),

$$
v=\frac{f\left(S_{\mathrm{n}}+A\right)}{n t}
$$

in which $f$ is the fraction of added ${ }^{35} \mathrm{~S}$ activity taken up during the bacterial incubation, $A$ is the concentration of added substrate in $\mathrm{mg} \mathrm{l}^{-1}$ (labeled + unlabeled), $t$ is the incubation time in $\mathrm{h}$ and $S_{\mathrm{n}}$ is natural substrate concentration in $\mathrm{mg} \mathrm{S}^{-1}$.

\section{Kinetic bioassay}

Rates of sulfate reduction and putrefaction were determined in diluted and undiluted samples by means of relationships developed by Wright and Hobbie (1966). As described by Wright and Hobbie, equations (1) and (2) may be substituted and rearranged to the slope intercept form,

$$
\frac{t}{f}=\frac{1 A}{V}+\frac{\left(K_{\mathrm{m}}+S_{\mathrm{n}}\right)}{V}
$$

Plotting $t / f$ on the ordinate and $A$ on the abscissa will yield a plot where $1 / V$ is the slope and $K_{m}+S_{n} / V$ is the intercept. The intercept in this case is a measure of turn-over for the substrate due to transport system uptake. Since at the intercept $A=0$, it follows from equations (1)-(3) that

$$
\frac{t}{f}=\frac{\left(K_{\mathrm{m}}+S_{\mathrm{n}}\right)}{V}=\frac{S_{\mathrm{n}}}{V_{t}}=T_{1}
$$

where $T$, is turnover time in $h$ and $V$, is the natural velocity due to Michaelis-Menten uptake or production. This procedure was followed for both sulfate and cysteine using the substrate concentration ranges indicated previously.

If continual regeneration and constant removal are assumed, the $T$, is the time required for an amount of substrate equal to that originally present to be replaced. If $S_{\mathrm{n}}$ is known, then

$$
v_{t}=\frac{S_{\mathrm{n}}}{T_{1}}
$$

If kinetic data from undiluted and diluted $(1: 2)$ samples are plotted in the form of equation (3), then $V$ and $K_{\mathrm{m}}+S_{\mathrm{n}}$ terms are obtained for both samples. Since the $\left(K_{m}+S_{n}\right)$ for the diluted sample is actually $\left(K_{\mathrm{m}}+S_{\mathrm{n}} / 2\right)$ in reference to the natural sample, then the two results can be combined in the form of simultaneous equations and $S_{\mathrm{n}}$ determined. This procedure was followed for both cysteine and sulfate.

\section{RESULTS}

\section{Hydrogen sulfide production}

Data from investigations of hydrogen sulfide pro-

\begin{tabular}{|c|c|c|c|}
\hline & \multicolumn{3}{|c|}{ Concentration (mg S1-1) } \\
\hline & Number & Mean & SD \\
\hline \multicolumn{4}{|c|}{ Sulfate } \\
\hline $\begin{array}{l}\text { pH } 7 \text { Phosphate extraction } \\
\text { and centrifugation }\end{array}$ & 10 & 10.5 & 2.0 \\
\hline Centrifugation only & 10 & 2.5 & 0.3 \\
\hline \multicolumn{4}{|c|}{ Cysteine } \\
\hline $\begin{array}{l}\text { pH } 10 \text { Phosphate extraction } \\
\text { and centrifugation }\end{array}$ & 16 & 0.26 & 0.21 \\
\hline $\begin{array}{l}\text { pH } 12 \text { Phosphate extraction } \\
\text { and centrifugation }\end{array}$ & 16 & 2.2 & 0.75 \\
\hline
\end{tabular}
duction from sulfate reduction and putrefaction are presented elsewhere (Dunnette et al., 1985; Dunnette, 1989). Briefly, total hydrogen sulfide production aver-
Table 1. Third sister sediment analysis results for sulfate and cysteine

aged approx. $2 \mathrm{mg} \mathrm{S}^{-1}$ day $^{-1}$ with putrefaction contributing an average of $15 \%(5-57 \%)$.

\section{Analytical data}

Analytical data are summarized in Table 1. As can be seen, the two analytical methods for each substrate produce quite different results. For sulfate, phosphate buffer extraction yielded values which were 4 times those of samples which were simply centrifuged. Similarly, with cysteine, pH 12 phosphate buffer extraction and centrifugation produced values which were, on the average, 8.5 times those of the $\mathrm{pH} 10$ buffer extraction.

\section{Adherence to Michaelis-Menten model}

A criterion for application of the kinetic bioassay procedure is that hydrogen sulfide production adheres to Michaelis-Menten kinetics when enzyne systems are saturated. If reaction rates of hydrogen sulfide production are relatively constant when sulfate or cysteine concentrations increase, then this suggests adherence to Michaelis-Menten kinetics.

For sulfate reduction the mean sulfide production rate was $0.0365 \mathrm{mg} \mathrm{S} \mathrm{I}^{-1} \mathrm{~d}^{-1}$ with a SD of 0.0040 . For cysteine the mean sulfide production rate was $0.0415 \mathrm{mg} \mathrm{S} \mathrm{l}^{-1} \mathrm{~d}^{-1}$ with a SD of 0.0070 . The data (fairly low standard deviations) suggest that hydrogen sulfide production from sulfate reduction adheres to Michaelis-Menten kinetics, but appear less clear for putrefaction.

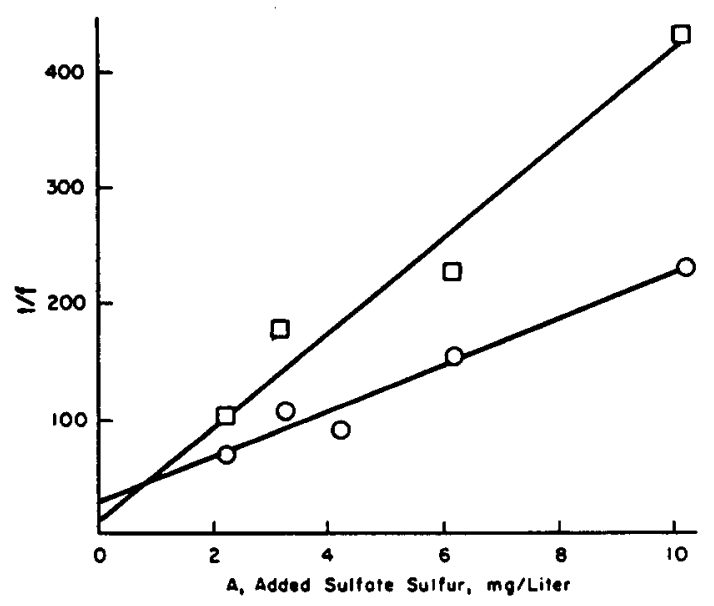

Fig. 1. $t / f$ as a function of added sulfate sulfur. $\square$, Diluted series; $O$, undiluted series. 


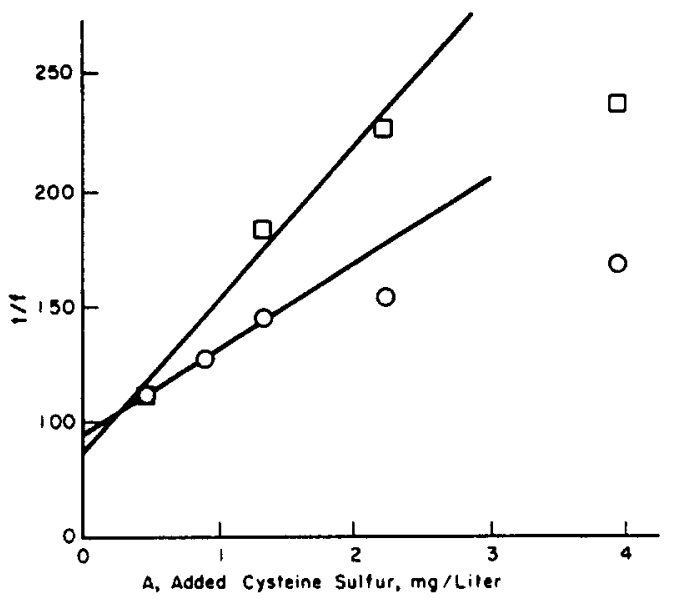

Fig. 2. $t / f$ as a function of added cysteine sulfur. $\square$, Diluted series; $O$, undiluted series.

\section{Kinetic bioassay}

A plot of $t / f$ vs total added substrate is given for diluted and undiluted samples for both sulfate and cysteine in Figs 1 and 2. The kinetic parameters obtained from these plots of equation (3) are given in Table 2. As can be seen, $V$ values of the diluted series are one-half the $V$ values of the undiluted series. This is evidence that hydrogen sulfide production was not disturbed by the dilution process. Data from the sulfate determination will be used to illustrate use of simultaneous equations to estimate $S_{\mathrm{n}}$. The intercepts $\left(K_{\mathrm{m}}+S_{\mathrm{n}}\right) / \mathrm{V}$ and slopes $(1 / \mathrm{V})$ may be estimated from Figs 1 and 2 and these are given in Table 2. Using these values the following equations are solved simultaneously:

undiluted

$$
\frac{K_{\mathrm{m}}+S_{\mathrm{n}: 2}}{0.050}=27
$$

diluted

$$
\frac{K_{\mathrm{m}}+S_{\mathrm{n}, 2}}{0.024}=13
$$

Solution yields an $S_{\mathrm{n}}$ of $2.08 \mathrm{mg} \mathrm{S}^{-1}$ for sulfate

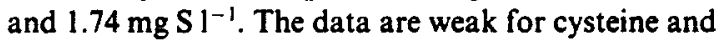
this may reflect the diversity of organisms involved in putrefactive production of hydrogen sulfide as compared to sulfate reducers (see Discussion below).

The negative $K_{\mathrm{m}}$ values obtained from solution of the equations is inconsistent with Michaelis-Menten kinetics and of concern, although the kinetic bioassay approach applied by others has produced results
Table 3. Comparison of kinetic bioassay and analytical chemistry results

\begin{tabular}{lcc}
\hline & $\begin{array}{c}\text { Sulfate } \\
\left(\mathrm{mg} \mathrm{S} \mathrm{I}^{-1}\right)\end{array}$ & $\begin{array}{c}\text { Cysteine } \\
\left(\mathrm{mg} \mathrm{S1}^{-1}\right)\end{array}$ \\
\hline Kinetic bioassay & 2.08 & 1.74 \\
Chemical method 1 & $10.5 \pm 0.95(n=10)$ & $0.3 \pm 0.05(n=16)$ \\
Chemical method 2 & $2.5 \pm 0.23(n=10)$ & $2.2 \pm 0.35(n=16)$ \\
\hline
\end{tabular}

which do not preclude the possibility of negative $K_{\mathrm{m}}$ values (Wright and Hobbie, 1966).

A comparison of kinetic bioassay and analytical chemistry results is given in Table 3 . In the case of both cysteine and sulfate, chemical method number 2 agreed most closely with kinetic bioassay results and in both cases the results were about $20-30 \%$ less than the chemical values. Results indicate that chemical method 2 is more appropriate in both cases as a measure of natural substrate concentration, $S_{\mathrm{n}}$.

Using the kinetic bioassay procedure described may also avoid criticisms often associated with tracer measurements, i.e. that addition of labeled material may significantly alter the natural substrate concentration and that rates measured with labeled substrate are not true rates. Use of the described approach will allow estimation of sulfate reduction rates in waters or sediments which formerly were precluded from tracer investigations due to low sulfate levels.

\section{DISCUSSION}

In the work described here it was necessary to estimate rates of hydrogen sulfide production from two different routes - sulfate reduction and putrefaction. This required knowledge of natural substrate concentrations $\left(S_{\mathrm{n}}\right)$ for sulfate and cysteine, respectively. Attempts to analyze for sulfate or cysteine in sediment yieided quite different results depending upon the technique chosen to estimate the "available" fraction. Extraction of sediment with phosphate buffer at various $\mathrm{pHs}$ gave results which differed up to $800 \%$ from analyses conducted on centrifuged sediment with no prior extraction. It thus became clear that accurate estimation of biotransformation rates in sediment required some form of bioassay information which more directly indicated actual "available" substrate.

The kinetic bioassay procedure of Wright and Hobbie (1966) was used for this purpose. The method has been used extensively to measure microbial biotransformations in sediment (Baker et al., 1982; Griffiths et al., 1977; King and Klug, 1982; Torien and Covari, 1983; Ferroni and Leduc, 1984) and in the work described here and involved measuring

Table 2. Kinetic parameters calculated for cysteine and sulfate bioassay

\begin{tabular}{lccccc}
\hline & \multicolumn{2}{c}{ Sulfate } & & \multicolumn{2}{c}{ Cysteine } \\
\cline { 2 - 3 } \cline { 5 - 6 } Parameter & Undiluted & Diluted & & Undiluted & Diluted \\
\hline$m$ (slope) $\left(\mathrm{h}^{\prime} \mid \mathrm{mg}^{-1}\right)$ & 20.0 & 42.2 & & 31.8 & 64.9 \\
$V\left(\mathrm{mg} \mathrm{h}^{-1}\right)$ & 0.050 & 0.024 & & 0.032 & 0.016 \\
$K_{\mathrm{m}}+S_{\mathrm{n}}(\mathrm{h})\left(T_{r}\right)$ & 27 & 13 & & 45 & 36 \\
$S_{\mathrm{n}}\left(\left.\mathrm{mg}\right|^{-1}\right)$ & 2.08 & & & 1.74 & \\
\hline
\end{tabular}


biotransformation rates at various added substrate concentrations in both diluted and undiluted samples and using these results to solve a set of simple simultaneous equations based on the MichaelisMenten enzyme kinetics model. Since the "centrifuged only" analytical procedure for sulfate provided results which most closely matched results obtained by the kinetic bioassay experiments, this procedure (involving simple centrifugation without extraction) was accepted as best representing sulfate $S_{\mathrm{n}}$. For cysteine it was found that simple centrifugation yielded undetectable levels but that phosphate extraction at elevated $\mathrm{pH}$ gave values that agreed closely with bioassay results.

Hypolimnetic sulfate data support the results obtained in these experiments for sulfate. Epilimnetic sulfate averaged $3.7 \pm 1.0 \mathrm{mg} \mathrm{S} \mathrm{I}^{-1}(n=10)$ and hypolimnetic sulfate (obtained immediately adjacent to the sediment) averaged $4.2 \pm 0.04 \mathrm{mg} \mathrm{SI}^{-1}$ found in water overlying the sediment represents a maximum expected sediment concentration. The bioassay sulfate value was $2.08 \mathrm{mg} \mathrm{S} \mathrm{I}^{-1}$ and chemical methods 1 (buffer extracted) and 2 (non-extracted) yielded 10.5 and $2.5 \mathrm{mg} \mathrm{S}^{-1}$, respectively. The bioassay sulfate value of $2.08 \mathrm{mg} \mathrm{S} \mathrm{I} \mathrm{I}^{-1}$ is consistent with the hypolimnetic value of 4.0 (considering sulfate reduction would be expected to deplete sulfate) and the choice of chemical method 2 as a reasonable indicator of sediment sulfate "availability" for sulfate reduction.

When applying kinetic bioassay results to the interpretation of chemical analytical data the question of applicability and limitations of the MichaelisMenten equation arises. Stanley and Staley (1977) observed adherence to Michaelis-Menten kinetics among several types of bacteria in pulp mill wastes. Wright (1974) found that the Michaelis-Menten equation fits the data more closely when the population is relatively active and dense. Krambeck (1979) points out that theoretically the Michaelis-Menten equation can approximate plankton cell kinetics only “... if all the opposing effects involved in the complex reaction system are correspondingly balanced, if the incubation time is short because of changes in the incubation population, and if the incubation itself does not introduce too great alteration of the natural conditions." The methodology described in this investigation was consistent with these criteria. Krambeck (1979) further states that calculation of $S_{n}$ will result in reasonably accurate results only when added substrate stays within the range of limiting concentrations $\left(K_{\mathrm{m}}+S_{\mathrm{n}}\right)$. Ferroni et al. (1983) used the method in simulated acid rain studies. Caldwell (1977) stated that interpretation of methods based on the Michaelis-Menten equation is "problematic" and Williams (1973) pointed out that mixed cultures may adhere to Michaelis-Menten kinetics under some conditions but that greater deviation may be expected as the heterogeneity of populations increases. Since relatively few bacterial species engage in dissimilative sulfate reduction to any great extent one might expect the deviation to be minimal. This was in fact observed as shown in Fig. 1. There are, however, many more species capable of producing hydrogen sulfide from cysteine and this fact supports the greater deviation for putrefaction observed as shown in Fig. 2.

Prior to kinetic bioassay experiments, work was undertaken to evaluate adherence to the MichaelisMenten equation. Results suggest that under the conditions of the experiments, hydrogen sulfide production from sulfate reduction and putrefraction both adhere to the Michaelis-Menten model although the evidence is less clear for putrefaction and negative $K_{\mathrm{m}}$ values are inconsistent with the model. Nevertheless, the results obtained in this study indicate that natural substrate concentrations $\left(S_{\mathrm{n}}\right)$ estimated by chemical analytical methods in heterogeneous media such as soil or sediment should preferably be supplemented with biological availability data such as that generated from the kinetic bioassay procedure described here. However, interpretations of kinetic bioassay information must be tempered by an appreciation of the limiting factors such as those discussed in detail by Krambeck (1979). Finally, the use of the kinetic bioassay procedure allows one to demonstrate the effect of labeled substrate addition on biotransformations of interest and could extend the range of waters investigated with tracers to those with lower concentrations of natural substrate.

Acknowledgements-Environmental Sciences and Resources Doctoral Program Publication No. 249. This study was supported in part by National Institute of Health and Environmental Protection Agency grants 5TO1-EC0030 and SP3-WP-177, respectively.

\section{REFERENCES}

Baker M. D., Innis W. E., Mayfield C. I. and Wong P. T. S. (1982) The effect of $\mathrm{pH}$ on the growth and activity of heterotrophic sediment microorganisms. Chemosphere 11, 973-983.

Caldwell D. E. (1977) The planktonic microflora of lakes. Crit. Rev. Microbiol. 5, 305-370.

Dunnette D. A. (1989) Origin of hydrogen sulfide in freshwater sediments. In Biogenic Sulfur in the Environment (Edited by Saltzman E. S. and Cooper W. J.), pp. 72-78. American Chemical Society Washington, DC.

Dunnette D. A., Chynoweth D. P. and Mancy K. H. (1985) The source of hydrogen sulfide in anoxic sediment. Wat. Res. 19, 875-884.

Ferroni G. D. and Luduc L. G. (1984) The unreliability of the kinetic approach to measuring bacterial mineralization activities at low in situ temperatures in an acidic aquatic environment. Wat. Res. 18, 1185-1188.

Ferroni G. D., Leduc L. G. and Choquet C. G. (1983) Preliminary studies on the use of the heterotrophic activity method in simulated acid rain investigations of aquatic environments. Wat. Res. 17, 1379-1384.

Freney J. R., Barrow N. J. and Spencer K. (1962) A review of certain aspects of sulfur as a soil constituent and plant nutrient. PI. Soil 17, 295-309.

Freney J. R., Melville G. E. and Williams C. H. (1969) Extraction, chemical nature and properties of soil organic sulfur. J. Sci. Fd Agric. 20, 440. 
Griffiths R. P., Hayasaka S. S., McNamara T. M. and Morita R. Y. (1977) Comparison between two methods of assaying relative microbial activity in marine environments. Appl. envir. Microbiol. 34, 801-805.

Hobbie J. E. and Crawford C. C. (1969) Respiration corrections for bacterial uptake of dissolved organic compounds in natural waters. Limnol. Oceanogr. 14, $528-532$.

Jordan H. V. and Ensminger L. E. (1958) The role of sulfur in soil fertility. In Advances in Agronomy, Vol. X. Academic Press, New York.

Kamprath E. J., Nelson W. L. and Fitts J. W. (1956) The effect of $\mathrm{pH}$, sulfate and phosphate concentrations on the absorption of sulfate by soils. Soil Sci. Soc. Proc. 20, 463-466.

King G. M. and Klug M. J. (1982) Glucose metabolism in sediments of a eutrophic lake: tracer analysis of uptake and product formation. Appl. envir. Microbiol. 44, $1308-1317$

Krambeck C. (1979) Applicability and limitations of Michaelis-Menten equation in microbial ecology. Arch. Hydrobiol. 12, 64-76.

Lowe L. E. (1964) An approach to the study of the sulfur status of soils and its application to selected Quebec soils. Can J. Soil Sci. 44, 176-179.

Lowe L. E. (1965) Sulfur fractions of selected Alberta soil profiles of the Chernozenic and Podzolic orders. Can. $J$. Soil Sci. 45, 297-303.

McLaren A. D. and Peterson G. H. (1967) Soil Biochemistry. Dekker, New York.

Melville G. E., Freney J. R. and Williams C. H. (1969) Investigations of the use of a chelating resin for the extraction of sulfur from soil. J. Sci. Fd Agric. 20, 203-206.

Monod J. (1958) Recherches sur la Eroissance des Cultures Bacteriennes, These, 2 edition. Hermann, Paris.

Parsons T. R. and Strickland J. D. H. (1962) On the production of particulate organic carbon by heterotrophic processes in sea water. Deep Sea Res. 8, 211-222.

Paul E. A. and Schmidt E. L. (1960) Relative release and retentiveness of soil phosphates. Soil Sci. Soc. Am. Proc. 24, 195.

Paul E. A. and Schmidt E. L. (1961) Formation of free amino acids in rhizosphere and nonrhizosphere soil. Soil Sci. Soc. Am. Proc. 25, 259.

Pinck L. A., Dyal R. S. and Allison F. E. (1954) Protein-montmorillonite complexes, their preparation and the effects of soil microorganisms on their decomposition. Soil Sci. 78, 109-118.

Stanley P. M. and Staley J. T. (1977) Acetate uptake by aquatic bacterial communities measured by autoradiography and filterable radioactivity. Limnol. Oceanogr. 22, 26-37.

Torien D. F. and Cavari B. (1982) Effect of temperature on heterotrophic glucose uptake, mineralization, and turnover rates in lake sediments. Appl. entir. Microbial. 43, $1-5$.

Williams P. J. (1973) The validity of the application of simple kinetic analysis to heterogeneous microbial populations. Limnol. Oceanogr. 18, 158-165.

Wright R. T. and Hobbie J. E. (1966) Use of glucose and acetate by bacteria and algae in aquatic ecosystems. Ecology 47, 447-464. 